\title{
Pengaruh Dukungan Keluarga dan Teman Sebaya terhadap Ibu Menyusui Neonatus di Rumah Sakit: Telaah Literatur
}

\author{
Regina Natalia $^{1 *}$, Yeni Rustina ${ }^{2}$ \\ ${ }^{1}$ Prodi Magister Ilmu Keperawatan, Fakultas Ilmu Keperawatan, Universitas Indonesia, Depok, Jawa Barat, Indonesia \\ ${ }^{2}$ Fakultas Ilmu Keperawatan, Universitas Indonesia, Depok, Jawa Barat, Indonesia \\ *Email Korespondensi: reginanatalia9@gmail.com
}

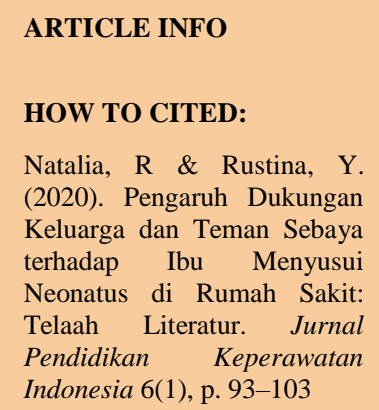

\section{ABSTRAK}

Pemberian ASI pada neonatus di rumah sakit mengalami banyak tantangan. Sementara itu, mempertahankan pemberian ASI dapat meningkatkan status kesehatan bayi, menurunkan morbiditas dan mortalitas neonatal. Intervensi untuk mempertahankan menyusui selama masa perawatan diantaranya dukungan menyusui dari keluarga dan teman sebaya. Tujuan penulisan artikel adalah untuk menelaah pengaruh intervensi dukungan keluarga dan teman sebaya terhadap ibu menyusui neonatus di rumah sakit. Artikel ini menggunakan pendekatan telaah literatur tahun 2009-2019. Telaah literatur dilakukan terhadap sembilan artikel yang memenuhi kriteria inklusi menunjukkan bahwa sumber dukungan menyusui dapat diperoleh dari keluarga dan teman sebaya. Dukungan menyusui dari pasangan, nenek, dan teman sebaya direkomendasikan untuk ibu-ibu berisiko menghentikan menyusui bayi. Dukungan menyusui yang bersumber dari keluarga dan teman sebaya memberi dampak positif terhadap peningkatan pengetahuan, sikap dan praktik menyusui. Peningkatan proporsi pemberian ASI, durasi menyusui, dan efikasi diri keluarga dalam membantu ibu menyusui. Perawat dapat menggunakan intervensi dukungan menyusui yang bervariasi sesuai dengan kondisi ibu untuk mempromosikan pemberian ASI pada neonatus di rumah sakit.

Kata Kunci: Ayah, dukungan, keluarga, menyusui, nenek, sebaya

\begin{abstract}
Breastfeeding newborns in hospitals experiences many challenges. Meanwhile, maintaining breastfeeding can improve a baby's health status, reduce neonatal morbidity and mortality. Interventions in order to breastfeeding during the treatment period include breastfeeding support from family and peers. This literature review aim to examine the effect of family and peer support on breastfeeding mothers in the hospital. This article uses a literature review approach from 2009-2019. Literature review conducted on nine articles that met the inclusion criteria shows that breastfeeding support can be obtained from family and peers. Breastfeeding support from partners, grandmothers, and peers is recommended for mothers at risk of stopping breastfeeding babies. Breastfeeding support sourced from family and peers has a positive impact on improving breastfeeding knowledge, attitudes and practices. Increasing the proportion of breastfeeding, duration of breastfeeding, and family self-efficacy in helping breastfeeding mothers. Nurses can use breastfeeding support interventions that vary according to the mother's condition to promote breastfeeding for newborns in the hospital.
\end{abstract}

Keywords: Breastfeeding, family, father, grandmother, peer, support 
Natalia, R \& Rustina, Y. | Pengaruh Dukungan Keluarga dan Teman Sebaya terhadap Ibu Menyusui Neonatus...

\section{PENDAHULUAN}

Kelahiran merupakan suatu proses transisi kehidupan bayi dari dalam rahim ke kehidupan di luar rahim. Dukungan kehidupan yang diberikan ibu kepada bayi terputus sejak bayi dilahirkan. Selama proses adaptasi, neonatus akan mengalami berbagai masalah kesehatan sesuai dengan pertumbuhan dan perkembangan bayi (Horbar et al., 2015). Beberapa masalah yang terjadi pada neonatus diantaranya masalah pernapasan, infeksi, kekurangan gizi, dan masalah yang timbul akibat komplikasi kelahiran bayi berat lahir rendah (Lawn et al., 2014) dan prematuritas (WHO, 2012). Masalah-masalah tersebut berkontribusi menyebabkan tingginya angka kematian neonatal (Lawn et al., 2014; WHO, 2014). Hal ini terlihat dari angka kematian neonatal secara global pada tahun 2017 diprediksi sekitar $18(17,20)$ per 1.000 kelahiran hidup (United Nations Children's Fund, World Health Organization, World Bank Group, \& United Nations, 2018).

Masalah kesehatan neonatus dapat dikurangi dan diatasi dengan cara memberikan perawatan terbaik selama bayi di hospitalisasi untuk meningkatkan status kesehatan bayi. Hospitalisasi memberikan dampak positif bagi status kesehatan neonatus secara umum, namun hospitalisasi juga berdampak buruk pada neonatus. Menurut Horbar et al. (2015) selama periode rawat neonatus terutama bayi berat lahir rendah atau bayi prematur cenderung mengalami kesulitan dalam meningkatkan berat badan. Upaya untuk meningkatkan berat badan bayi adalah dengan memberikan ASI yang baik bagi pertumbuhan bayi (Thakur et al., 2012).

Kenyataannya pemberian ASI pada bayi di rumah sakit menemukan beberapa masalah diantaranya masalah pemisahan akibat ibu dan bayi dirawat pada tempat yang berbeda (Luong, Nguyen, Thi, Carrara, \& Bergman, 2016), ibu atau bayi dalam keadaan sakit (Kositamongkol, Nanthakomon, \& Nukaw, 2019), ibu khawatir memompa ASI dari payudara (Ikonen, Paavilainen, \& Kaunonen, 2015), masalah ASI yang kurang, dan masalah menyusui menjadi alasan untuk tidak melanjutkan pemberian ASI (Al
Juaid, Binns, \& Giglia, 2014). Cleminson, Oddie, Renfrew, dan McGuire (2014) menjelaskan alasan umum ibu tidak melanjutkan menyusui dini adalah kekhawatiran akan pertumbuhan bayi, kecukupan bayi mendapatkan ASI, dan persepsi negatif tentang menyusui yang ada dalam pendangan keluarga, teman sebaya dan masyarakat.

Pemberian ASI pada neonatus di Indonesia juga mengalami masalah yang menyebabkan durasi pemberian ASI ekslusif masih belum memenuhi rekomendasi nasional dan global. Data Survei Demografi dan Kesehatan Indonesia tahun 2017 yang dirilis oleh Badan Kependudukan dan Keluarga Berencana Nasional, Badan Pusat Statistik, Kementerian Kesehatan, dan USAID (2018) menunjukkan 52\% bayi (usia kurang dari enam bulan) mendapat ASI ekslusif, namun median durasi pemberian ASI ekslusif adalah tiga bulan. Selain itu, $44 \%$ neonatus mendapat makanan pralaktasi dalam tiga hari setelah lahir. Hal ini mencerminkan bahwa pada masa awal kehidupan neonatus masih banyak yang belum menerima ASI saja. Sementara itu standar global yang ditetapkan WHO (2018) yaitu minimal $80 \%$ neonatus hanya menerima ASI saja selama masa perawatan di fasilitas pelayanan kesehatan. Oleh sebab itu, dibutuhkan intervensi untuk memberikan dukungan menyusui yang dapat mempromosikan ASI bagi neonatus di rumah sakit.

Beberapa peneliti luar negeri telah menggunakan sumber dukungan menyusui dari keluarga dan teman sebaya. Adapun tujuan pemberian dukungan menyusui diantaranya untuk meningkatkan tingkat dan durasi pemberian ASI ekslusif (Bootsri \& Taneepanichskul, 2017; Oliveira et al., 2014) sehingga meningkatkan jumlah neonatus yang mendapatkan ASI sebagai nutrisi terbaik. Mengingat pentingnya memberikan ASI bagi neonatus dan mencapai keberhasil pemberian ASI ekslusif hingga usia enam bulan, maka kajian literatur ini dilakukan untuk menelaah intervensi dukungan menyusui dari sumber non tenaga kesehatan. Artikel ini menggunakan metode telaah literatur yang bertujuan untuk menelaah efektivitas dukungan menyusui oleh keluarga dan teman sebaya dalam meningkatkan hasil ibu 
menyusui neonatus di tatanan pelayanan kesehatan sekunder.

\section{METODE}

Penelusuran literatur untuk artikel ini menggunakan pendekatan yang sistematis dari database Google Scholar dan ScienceDirect. Penelusuran artikel menggunakan kata kunci "father", "grandmother", "family", "peer", "support", dan "breastfeeding". Terdapat 32 artikel terpilih dari 12 negara meliputi Finlandia,
Kanada, Australia, Perancis, Swedia, Amerika Serikat, Thailand, Brazil, Malaysia, Cina, Sri Lanka, dan Turki. Sembilan artikel dari 32 yang memenuhi kriteria yaitu artikel: berbahasa Inggris, terbit tahun 2009-2019, membahas tentang dukungan keluarga dan dukungan sebaya dalam menyusui pada masa postpartum bagi ibu bayi baru lahir, ibu bayi berat lahir rendah, dan ibu bayi prematur. Selain itu, penelitian yang diambil adalah penelitian yang menggunakan desain quasi experimental, RCT dan kualitatif (lihat Skema 1).

Artikel teridentifikasi dari database online ScienceDirect 5.251artikel dan Google Scholar 18.070 artikel

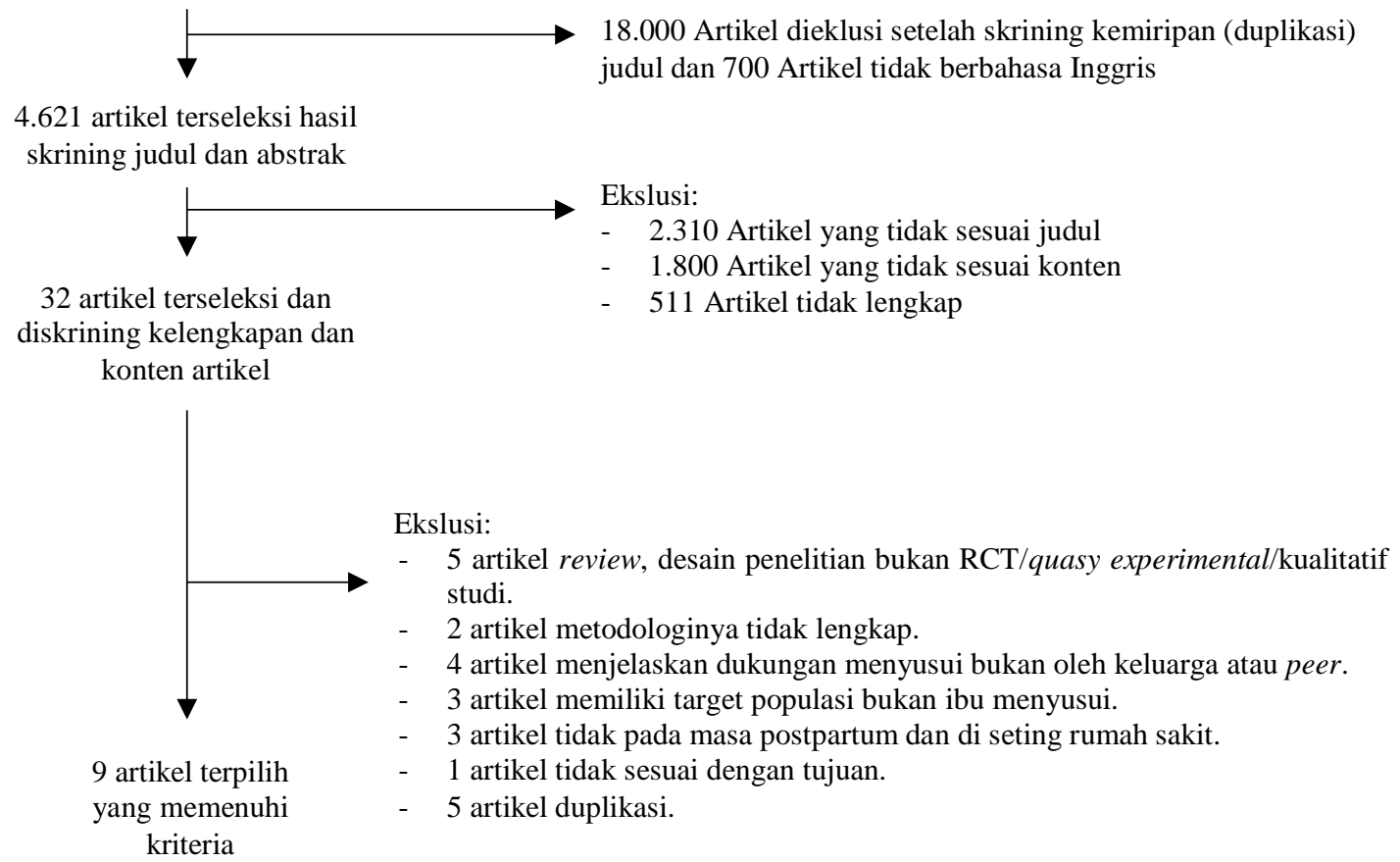

Skema 1. Studi Terpilih untuk Pemberian Dukungan bagi Ibu Menyusui

Artikel ditinjau menggunakan metode penilaian telaah sistematik Joanna Briggs Institute (Tufanaru, Munn, Aromataris, Campbell, \& Hopp, 2017) untuk studi desain RCT dan quasi experimental. Sementara itu, artikel yang menggunakan desain studi kualitatif menggunakan metode penilaian COREQ. Artikel literature review dan artikel penelitian yang tidak sesuai dengan desain yang diharapkan masuk dalam kriteria ekslusi. Selain itu, artikel yang tidak memiliki struktur lengkap, populasi penelitian adalah ayah atau nenek, pemberi dukungan menyusui adalah konselor laktasi dari tenaga kesehatan, serta penjelasan yang tidak lengkap mengenai desain, sampling, saturasi, dan analisis data akan diekslusikan.

\section{HASIL}

Hasil penelusuran artikel dalam 10 tahun terakhir ditemukan enam artikel penelitian RCT, 
Natalia, R \& Rustina, Y. | Pengaruh Dukungan Keluarga dan Teman Sebaya terhadap Ibu Menyusui Neonatus...

satu artikel quasi experimental, dan dua artikel penelitian kualititatif (Tabel 3). Artikel studi eksperimental yang memenuhi kriteria inklusi dinilai kualitas metodologis menggunakan protokol Joanna Briggs Institute (Tabel 1 dan 2). Setelah menelaah sembilan artikel, ditemukan bahwa dukungan menyusui berpengaruh pada peningkatan hasil ibu menyusui neonatus. Selanjutnya temuan tersebut dijelaskan dalam tiga subtema, yaitu: sumber dan dukungan menyusui serta variasi intervensi.
Temuan sumber dukungan menyusui dari lima artikel menggunakan intervensi pelibatan pendukung sebaya, satu artikel menggunakan intervensi dukungan menyusui dari ayah dan tiga artikel menjelaskan dukungan menyusui dari nenek. Intervensi dalam studi dapat dikategorikan menjadi intervensi berbasis teknologi, intervensi berbasis informasi dan intervensi berbasis hubungan yang saling mendukung (Supportive Relationships). Ketiga kategori intervensi tersebut digunakan secara tunggal atau kombinasi sehingga dapat memberi dukungan bagi ibu menyusui.

Tabel 1. Kualitas Metodologis Studi Quasi Eksperimental

\begin{tabular}{|c|c|c|c|c|c|c|c|c|c|c|}
\hline Penulis & P1 & $\mathbf{P 2}$ & P3 & $\mathbf{P 4}$ & P5 & P6 & P7 & P8 & P9 & Jumlah Ya \\
\hline (Bootsri \& Taneepanichskul, 2017) & $\mathrm{Y}$ & $\mathrm{Y}$ & $\mathrm{Y}$ & $\mathrm{Y}$ & $\mathrm{Y}$ & $\mathrm{Y}$ & $\mathrm{Y}$ & $\mathrm{Y}$ & $\mathrm{Y}$ & 9 \\
\hline
\end{tabular}

Akses pertanyaan di https://reviewersmanual.joannabriggs.org/

Tabel 2. Kualitas Metodologis Studi RCT

\begin{tabular}{lcccccccccccccc}
\hline \multicolumn{1}{c}{ Penulis } & P1 & P2 & P3 & P4 & P5 & P6 & P7 & P8 & P9 & P10 & P11 & P12 & P13 & Jumlah Ya \\
\hline (Niela-Vilen et al., 2016) & Y & Y & Y & Y & Y & T & Y & Y & Y & Y & Y & Y & Y & 12 \\
\hline (da Silva et al., 2016) & Y & Y & Y & Y & Y & Y & Y & Y & Y & Y & Y & Y & Y & 13 \\
\hline (Martinez-Brockman et al., 2018) & Y & Y & Y & Y & T & Y & Y & Y & Y & Y & Y & Y & Y & 12 \\
\hline (Abbass-Dick et al., 2015) & Y & Y & Y & Y & T & Y & Y & Y & Y & Y & Y & Y & Y & 12 \\
\hline (Oliveira et al., 2014) & Y & Y & Y & Y & T & Y & Y & Y & Y & Y & Y & Y & Y & 12 \\
\hline (Meglio et al., 2010) & Y & Y & Y & Y & Y & Y & Y & Y & Y & Y & Y & Y & Y & 13 \\
\hline
\end{tabular}

Keterangan: $\mathrm{P}=$ Pertanyaan; $\mathrm{Y}=\mathrm{Ya}$; $\mathrm{T}=$ Tidak; TJ=Tidak Jelas

Akses pertanyaan di https://reviewersmanual.joannabriggs.org/

Penulis juga menemukan bahwa dukungan menyusui dari ayah, nenek, dan teman sebaya dapat berdampak positif pada tingkat pemberian ASI ekslusif, durasi pemberian ASI ekslusif, lama menyusui, pengeluaran ASI, pengetahuan, sikap dan praktik menyusui, dukungan sosial, efikasi diri ayah, dan keberlanjutan menyusui periode awal postpartum. Terdapat beberapa penelitian yang tidak menunjukkan efek signifikan dari intervensi pendukung sebaya, ayah, dan nenek. Pada studi kualitatif, beberapa tema yang muncul menunjukkan bahwa ibu menyusui mendapat dukungan yang baik selama periode perawatan di rumah sakit hingga di rumah sehingga tercapai keberlanjutan menyusui.

Tabel 3. Penelitian Dukungan Menyusui dari Keluarga dan Teman Sebaya

\begin{tabular}{|c|c|c|c|}
\hline Artikel & Desain dan Sampel & Intervensi yang Dilakukan & Hasil \\
\hline $\begin{array}{l}\text { Niela-Vilen, } \\
\text { Axelin, Melender, } \\
\text { Loyttyniemi, dan } \\
\text { Salantera (2016) } \\
\text { Finlandia }\end{array}$ & $\begin{array}{l}\text { Randomized Controlled Trial (RCT) } \\
\text { Sampel: } \\
124 \text { ibu bayi prematur ( }<35 \text { minggu) }\end{array}$ & $\begin{array}{l}\text { Pada kelompok eksperimen: } \\
\text { membentuk kelompok dukungan sebaya } \\
\text { menyusui di Facebook }(\mathrm{Fb}) \text {. Ibu yang } \\
\text { mendaftar di Fb-grup mendapatkan } \\
\text { dukungan menyusui dari tiga pendukung } \\
\text { sebaya yang berpengalaman dalam } \\
\text { menyusui bayi prematur. Didalam grup } \\
\text { terdapat seorang bidan yang bertugas } \\
\text { menjawab pertanyaan tentang menyusui. } \\
\text { Pada kelompok kontrol: } \\
\text { Dukungan menyusui rutin di NICU. }\end{array}$ & $\begin{array}{l}\text { - Intervensi dukungan sebaya di media sosial } \\
\text { tidak berpengaruh pada durasi menyusui } \\
\text { ekslusif yaitu } 0 \text { bulan pada kedua kelompok } \\
\text { - Tidak berpengaruh pada durasi menyusui di } \\
\text { kelompok intervensi dan kelompok kontrol } \\
\text { adalah } 3 \text { bulan vs } 4-3 \text { bulan. } \\
\text { - Tidak ada pengaruh intervensi pada durasi } \\
\text { pengeluaran ASI ( } 4 \text { bulan pada kelompok } \\
\text { intervensi vs 3-8 bulan pada kelompok } \\
\text { kontrol. } \\
\text { - Intervensi tidak berpengaruh pada sikap } \\
\text { menyusui }(p=0,99) \text {. }\end{array}$ \\
\hline
\end{tabular}


Natalia, R \& Rustina, Y. | Pengaruh Dukungan Keluarga dan Teman Sebaya terhadap Ibu Menyusui Neonatus...

Tabel 3. Penelitian Dukungan Menyusui dari Keluarga dan Teman Sebaya (Lanjutan)

\begin{tabular}{|c|c|}
\hline Artikel & Desain dan Sampel \\
\hline $\begin{array}{l}\text { Niela-Vilen, } \\
\text { Axelin, Melender, } \\
\text { dan Salantera }\end{array}$ & $\begin{array}{l}\text { Penelitian kualitatif yang menggunakan } \\
\text { analisis tematik }\end{array}$ \\
\hline (2015) & Sampel: \\
\hline Finlandia & $\begin{array}{l}22 \text { ibu bayi prematur dan berpartisipasi } \\
\text { aktif dalam diskusi melalui posting } \\
\text { media sosial, tiga pendukung sebaya } \\
\text { dan bidan yang tergabung dalam } \\
\text { kelompok dukungan sebaya Facebook } \\
\text { yang digunakan dalam penelitian uji } \\
\text { klinis acak }\end{array}$ \\
\hline
\end{tabular}

Tiga tema utama:

Paradoks menyusui di rumah sakit memiliki 5 dimensi: (1) Pemulangan bayi secara dini dengan mengorbankan menyusui; (2) Risiko terhadap kesehatan bayi; (3) Berbagai dukungan perawat; (4) ASI sebelum menyusui; (5) Perawatan kanguru kurang dimanfaatkan untuk dukungan menyusui.

'Pemeriksaan Realitas' menyusui di rumah memiliki 3 dimensi: (1) Kebutuhan informas yang tidak terpenuhi dan kurangnya keterampilan; (2) Menyusui terus menjadi risiko bagi kesejahteraan bayi; (3) Peluang baru di rumah.

Pengalaman menyusui sebagai bagian dari menjadi seorang ibu meliputi pengalaman menyusui yang 'berhasil' atau 'tidak berhasil'.

\begin{tabular}{ll}
\hline Bootsri dan & Quasi-experimental \\
Taneepanichskul & \\
(2017) & Sampel: \\
Thailand & $\begin{array}{l}168 \text { responden (84 ibu remaja dan } 84 \\
\text { nenek) }\end{array}$
\end{tabular}

Pada kelompok eksperimen:

Program Experiential Learning with

Empowerment Strategies and Social

Support

(ELESSS) bagi nenek dari ibu remaja dalam sesi 6 jam (2 hari) kursus dilanjutkan sesi pembelajaran selama 1 jam di bangsal ibu nifas.

Pada kelompok kontrol:

Program rutin di klinik prenatal dan postnatal.

\begin{tabular}{ll}
\hline da Silva, Nunes, & RCT \\
$\begin{array}{l}\text { Schwartz, dan } \\
\text { Giugliani (2016) }\end{array}$ & $\begin{array}{l}\text { Sampel: } \\
\text { 323 ibu remaja, neonatus mereka dan } \\
\text { juga ibu mereka (nenek dari pihak ibu } \\
\text { remaja) yang tinggal bersama }\end{array}$
\end{tabular}

Pada kelompok eksperimen:

6 sesi konseling menyusui oleh tenaga kesehatan terlatih.

Sesi 1 (1 jam) konseling secara terpisah kepada ibu dan nenek di bangsal bersalin.

Lalu konseling secara bersamaan ibu dan nenek di rumah pada hari ke $7,15,30,60$, dan hari ke 120 paska melahirkan.

Pada kelompok kontrol:

Tidak diberi intervensi.

\begin{tabular}{ll}
\hline $\begin{array}{l}\text { Martinez- } \\
\text { Brockman et al. }\end{array}$ & RCT - Single blinded \\
$(2018)$ & Sampel: \\
& $\begin{array}{l}174 \text { ibu berpenghasilan rendah yang } \\
\text { ikut dalam program WIC BFPC }\end{array}$
\end{tabular}

Pada kelompok eksperimen:

Ibu menerima program standar ditambah

dengan intervensi Lactation Advice

Through Texting Can Help (LATCH)

berupa pengiriman

pesan teks melalui perangkat gawai.

Pada kelompok kontrol:

Ibu menerima program standar WIC-BFPC

(Women, Infants, and Children-

Breastfeeding Peer Concelors)

\begin{tabular}{ll}
\hline $\begin{array}{l}\text { Abbass-Dick, } \\
\text { Stern, Nelson, }\end{array}$ & RCT \\
Watson, dan & $\begin{array}{l}\text { Sampel primipara multikultural: } \\
\text { Dennis (2015) } \\
\text { 107 pasangan menerima perawatan } \\
\text { biasa dan 107 pasangan menerima } \\
\text { intervensi dukungan menyusui }\end{array}$ \\
Kanada &
\end{tabular}

Pada kelompok eksperimen:

Perawatan rutin pascapersalinan dan

dukungan menyusui co-parenting

multikomponen terdiri dari penyediaan

informasi meliputi: (1) 15 menit diskusi

dengan ahli laktasi, (2) Buklet co-parenting

dibawa pulang untuk kegiatan keterampilan

co-parenting, (3) Buklet menyusui dibawa pulang, (4) Video menyusui dan $c o-$

parenting berdurasi 11 menit, (5) Situs web

yang dapat diakses dan menyediakan informasi seputar menyusui, (6) Pengingat melalui e-mail yang dikirim pada satu dan tiga minggu paska melahirkan, dan (7) Panggilan telepon pada minggu ke dua postpartum.

Intervensi ELESSS efektif meningkatkan tingkat dan proporsi pemberian ASI ekslusif, durasi pemberian ASI ekslusif, pengetahuan, sikap, praktik menyusui, dan dukungan sosial yang dirasakan dari nenek selama 6 bulan pertama.

Tidak terdapat pengaruh yang signifikan pada pemeliharaan keberlangsungan menyusui pada usia anak 2 tahun antara kelompok intervensi dengan kelompok kontrol ( $29,9 \%$ vs $34,4 \%$; $\mathrm{p}=0,605$ ).

Pada kelompok kontrol:

Perawatan rutin pascapersalinan.

\begin{tabular}{ll}
\hline $\begin{array}{l}\text { Oliveira, } \\
\text { Giugliani, Santo, } \\
\text { dan Nunes (2014) }\end{array}$ & RCT \\
& $\begin{array}{l}\text { Sampel: } \\
\text { Brazil }\end{array}$ \\
& $\begin{array}{l}\text { mereka diambil secara acak } \\
\text { ditempatkan dalam empat kelompok: }\end{array}$ \\
& Kelompok B: tidak tinggal bersama \\
& nenek, tanpa intervensi; \\
& Kelompok A: tidak tinggal bersama \\
& nenek, dengan intervensi; \\
& Kelompok D: tinggal dengan nenek, \\
& tanpa intervensi, \\
& Kelompok C: tinggal dengan nenek, \\
& dengan intervensi. \\
\hline
\end{tabular}

Pada kelompok eksperimen:
1 sesi konseling untuk ibu dan

列 liakukan secara terpisah saat di rumah sakit dan dilanjutkan 5 sesi konseling di rumah secara bersamaan ibu dan nenek saat usia bayi 7, 15, 30, 60, dan 120 hari.

Pada kelompok kontrol:

Tanpa intervensi.

\author{
LACTH memiliki efek yang signifikan pada \\ waktu kontak pertama ibu dengan BFPC \\ $(\mathrm{p}=0,02)$. \\ - Dibandingkan kelompok kontrol, kelompok \\ intervensi lebih tinggi 2,79 kemungkinan \\ kontak langsung dengan BFPC atau kontak \\ dalam waktu 48 jam dibandingkan kontak \\ dalam 1 atau 2 minggu postpartum. \\ Tidak terdapat perbedaan signifikan tingkat \\ pemberian ASI ekslusif pada 2 minggu \\ postpartum $(\mathrm{p}=0,50)$. \\ Terdapat perbedaan positif yang signifikan pada \\ kelompok eksperiman yang mendapat intervensi \\ multikomponen dibandingkan dengan kelompok \\ kontrol dalam hal: Keberlanjutan menyusui \\ hingga 12 minggu postpartum $(\mathrm{P}=0,02)$, skor \\ efikasi diri ayah hingga 6 minggu postpartum \\ $(\mathrm{P}=0,03)$, ibu melaporkan pasangan mereka \\ memberi bantuan menyusui pada minggu \\ pertama $(\mathrm{P}=0,02)$, ibu puas dengan keterlibatan \\ ayah $(\mathrm{P}=0,04)$, dan ibu puas dengan informasi \\ tentang menyusui $(\mathrm{P}=0,001)$. Selanjutnya \\ perbedaan yang tidak signifikan antara kedua \\ kelompok terdapat pada keberlanjutan menyusui \\ pada 6 minggu pertama postpartum $(\mathrm{P}=0,06)$.
}


Natalia, R \& Rustina, Y. | Pengaruh Dukungan Keluarga dan Teman Sebaya terhadap Ibu Menyusui Neonatus...

Tabel 3. Penelitian Dukungan Menyusui dari Keluarga dan Teman Sebaya (Lanjutan)

\begin{tabular}{|c|c|c|c|}
\hline Artikel & Desain dan Sampel & Intervensi yang Dilakukan & Hasil \\
\hline $\begin{array}{l}\text { Meglio, } \\
\text { McDermott, dan } \\
\text { Klein (2010) } \\
\text { Kanada }\end{array}$ & $\begin{array}{l}\text { RCT, double-blind } \\
\text { Sampel: } \\
78 \text { ibu menyusui }\end{array}$ & $\begin{array}{l}\text { Pada kelompok eksperimen: } \\
\text { Ibu menerima panggilan telepon dari } \\
\text { pendukung sebaya pada hari ke dua, empat, } \\
\text { tujuh dan pada mingg ke dua, tiga, empat, } \\
\text { dan lima paska pulang dari rumah sakit. } \\
\text { Pada kelompok kontrol: } \\
\text { Ibu tidak menerima dukungan sebaya. }\end{array}$ & $\begin{array}{l}\text { Tidak ada perbedaan yang signifikan pada } \\
\text { durasi menyusui dalam kedua kelompok. } \\
\text { Namun, diantara ibu yang menyusui ekslusif } \\
\text { dalam kelompok intervensi dan kontrol (13 } \\
\text { vs } 11 \text { ) menunjukkan peningkatan durasi } \\
\text { menyusui (median } 35 \text { hari vs } 10 \text { hari; } \\
\mathrm{P}=0,004) \text {. }\end{array}$ \\
\hline $\begin{array}{l}\text { Rossman et al. } \\
\text { (2011) } \\
\text { Amerika Serikat }\end{array}$ & $\begin{array}{l}\text { Deskriptif kualitatif } \\
\text { Sampel: } 21 \text { partisipan yaitu ibu BBLSR } \\
\text { yang berpengalaman berhubungan } \\
\text { dengan konselor sebaya selama bayi di }\end{array}$ & - & $\begin{array}{l}\text { Tema utama terdiri dari: } \\
\text { 1. Making the connection } \\
\text { 2. Taking it in } \\
\text { 3. Making it personal }\end{array}$ \\
\hline 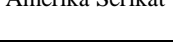 & rawat di NICU & & \\
\hline
\end{tabular}

\section{PEMBAHASAN}

\section{Sumber Dukungan Menyusui di Rumah Sakit}

Promosi menyusui bagi ibu yang melahirkan di unit pelayanan kesehatan merupakan hal utama yang harus dilakukan untuk mempromosikan pemberian ASI yang baik bagi neonatus, namun hal tersebut tidak mudah dilakukan terutama pada ibu kelompok risiko tinggi. Kelompok yang berisiko tidak melanjutkan pemberian ASI ekslusif secara dini diantaranya ibu remaja (Bootsri \& Taneepanichskul, 2017; da Silva et al., 2016; Oliveira et al., 2014), primipara (Abbass-Dick et al., 2015), ibu berpenghasilan rendah (MartinezBrockman et al., 2018), kelahiran bayi berat lahir rendah (Rossman et al., 2011), dan kelahiran prematur (Niela-Vilen et al., 2015; Niela-Vilen et al., 2016). Menurut rekomendasi dari WHO (2018), dukungan praktis, emosional, dan informasi harus diberikan kepada ibu menyusui untuk membantu mereka mengatasi kesulitan dalam menyusui dan mempertahankan menyusui. Dukungan tersebut dapat diberikan oleh tenaga kesehatan, konselor sebaya, keluarga, dan kelompok dukungan ibu-ke-ibu (WHO, 2018).

Di Indonesia, dukungan menyusui saat di rumah sakit dan di rumah juga diperoleh dari non tenaga kesehatan (informal). Studi fenomenologi yang dilakukan oleh Choiriyah, Hapsari, dan Lismidiati (2015) terhadap tujuh ibu menyusui bayi berat lahir rendah di kota Malang mengidentifikasikan bahwa ibu menyusui mendapatkan dukungan dari tenaga kesehatan dan dukungan dari pasangan, keluarga, dan teman sebaya agar dapat mempertahankan dan meningkatkan produksi ASI. Demikian juga dengan ibu menyusui BBLR di satu rumah sakit di Jakarta mendapatkan dukungan menyusui dari lingkungan sosial terdekat yaitu suami, keluarga dan teman (Widiastuti, Rustina, \& Agustini, 2019).
Hasil penelitian tersebut mengindikasikan bahwa pemberian edukasi harus juga melibatkan suami, keluarga, dan teman, sehingga mereka dapat memberikan dukungan dengan benar.

Peneliti di berbagai negara seperti Amerika Serikat, Kanada, Brazil, Finlandia, dan Thailand memanfaatkan suami (Abbass-Dick et al., 2015), nenek (Bootsri \& Taneepanichskul, 2017; da Silva et al., 2016; Oliveira et al., 2014), dan teman sebaya (Martinez-Brockman et al., 2018; NielaVilen et al., 2015; Niela-Vilen et al., 2016; Rossman et al., 2011) sebagai sumber pemberi dukungan bagi ibu menyusui mulai dari paska melahirkan di rumah sakit hingga di rumah. Dukungan menyusui dari suami dapat berupa keterlibatan dan bantuan dalam proses menyusui setelah suami menerima informasi tentang menyusui (Abbass-Dick et al., 2015). Dukungan dari nenek dalam bentuk dukungan sosial, memberikan informasi tentang menyusui, dan bantuan praktis dalam merawat bayi (Bootsri \& Taneepanichskul, 2017). Bentuk dukungan yang diberikan dari teman sebaya seperti bertukar pengalaman menyusui, memberi informasi menyusui, dan menyarankan ibu yang bermasalah dalam menyusui ke tenaga kesehatan (Meglio et al., 2010). Berbagai dukungan yang diberikan bertujuan membentuk dan meningkatkan kepercayaan diri ibu dalam menyusui (WHO, 2018) dan ibu menjadi termotivasi untuk menyusui sehingga akan meningkatkan produksi ASI (Widiastuti et al., 2019).

Penggunaan intervensi dukungan menyusui perlu memperhatikan aspek budaya untuk mencapai hasil yang lebih baik. Di Thailand, nenek yang tinggal serumah atau dekat dengan ibu remaja dan berpengalaman merawat bayi dianggap sebagai orang yang memiliki pengaruh dalam promosi menyusui pada ibu remaja. Salah satu 
program pemberdayaan nenek sebagai pemberi dukungan menyusui telah diuji oleh Bootsri dan Taneepanichskul (2017). Namun pada penelitian sebelumnya, pemanfaatan sumber dukungan dari nenek memiliki aspek yang kurang menguntungkan pada ibu remaja yang tinggal serumah dengan nenek. Hal ini disebabkan, ibu remaja kurang memiliki otonomi dalam mengikuti instruksi dan tanggung jawab penuh dalam menyusui bayi karena ibu kemungkinan dapat berbagi tugas dan tanggung jawab dengan nenek dalam merawat bayi (Oliveira et al., (2014). Di Indonesia, nenek juga memegang peranan penting dalam pengasuhan bayi/anak khususnya bagi mereka yang tinggal serumah. Pada yang memegang adat matrilineal, keluarga biasanya tinggal bersama dan nenek bisa menjadi seorang yang berpengaruh karena paling dihormati.

Sumber dukungan lain selain nenek adalah teman sebaya. Penggunaan dukungan menyusui dari teman sebaya memiliki tantangan spesifik yang harus diatasi. Meglio et al. (2010) menemukan keunikan berupa tingkat keikutsertaan pelatihan hingga tuntas sangat rendah karena pendukung sebaya cenderung drop out selama masa pelatihan. Tantangan kedua adalah intervensi dukungan sebaya tidak diberikan secara konsisten diantara para ibu. Selain itu, pendukung sebaya memiliki proporsi tanggung jawab diluar kemampuan pada tahap usia mereka. Dengan demikian, perlu memperhatikan aspek perkembangan dan komitmen diri pendukung sebaya sehingga dapat memberikan dukungan kepada ibu menyusui dalam jangka waktu yang lama.

\section{Dampak Dukungan Menyusui di Rumah Sakit}

Dukungan dari keluarga dan teman sebaya terbukti berdampak baik bagi ibu menyusui. Hal ini terlihat dari peningkatan signifikan pada pengetahuan, sikap, keterampilan dan durasi menyusui. Dukungan menyusui dari ayah berpengaruh pada peningkatan jumlah ibu menyusui pada minggu ke 12 postpartum, efikasi diri ayah, rasa puas ibu terhadap keikutsertaan ayah dalam memberi dukungan dan informasi tentang menyusui (Abbass-Dick et al., 2015). Dukungan menyusui dari anggota keluarga lain juga dapat berdampak pada praktik menyusui. Studi Bootsri dan Taneepanichskul (2017) melibatkan nenek dalam sesi pendidikan menyusui kepada ibu dapat meningkatkan pengetahuan dan pemahaman tentang menyusui serta meningkatkan dan mempertahankan durasi pemberian ASI ekslusif dan durasi menyusui dalam 6 bulan pertama. Selain itu, nenek memiliki kemampuan yang lebih baik untuk memberi dukungan sosial dan praktik bagi ibu menyusui. Hal tersebut sesuai dengan penelitian Oliveira et al. (2014) menunjukan peningkatan durasi menyusui ekslusif sebanyak 67 hari dari yang semula 36 hari menjadi 103 hari. Berbeda dengan hasil penelitian da Silva et al. (2016) yang melibatkan nenek dalam sesi konseling tidak menunjukkan adanya peningkatan prevalensi menyusui pada 2 tahun pertama meskipun peningkatan tersebut tampak pada satu tahun pertama. Perbedaan hasil ini kemungkinan disebabkan karena jenis intervensi yang diberikan, da Silva et al. (2016) hanya memberikan konseling. Namun demikian, intervensi dukungan menyusui tetap menjadi pilihan intervensi untuk meningkatkan pemberian ASI di rumah sakit.

Bentuk intervensi lain yang juga banyak digunakan untuk memberi dukungan menyusui adalah dukungan dari teman sebaya. Melalui konseling dan dukungan menyusui yang diberikan di unit neonatal sangat berperan pada pencapaian keberhasilan menyusui (Niela-Vilen et al., 2016). Beberapa dampak dukungan menyusui dari teman sebaya berdasarkan hasil temuan beberapa peneliti meliputi menyingkat waktu kontak dengan konselor sebaya (Martinez-Brockman et al., 2018) dan meningkatkan durasi menyusui diantara ibu yang memberi ASI ekslusif dalam kelompok perlakuan (Meglio et al., 2010). Walaupun demikian, dukungan sebaya belum dapat memperpanjang durasi menyusui (Meglio et al., 2010) atau pun menyusui ekslusif pada bulan pertama (Martinez-Brockman et al., 2018).

Kurangnya efek intervensi dukungan menyusui dapat disebabkan oleh pendukung sebaya kurang terlibat aktif dalam kelompok dukungan sebaya dan sikap menyusui yang cenderung menurun selama masa tindak lanjut (Niela-Vilen et al., 2016). Rencana dan niat yang kuat untuk menyusui dapat membuat ibu tetap bertahan melanjutkan menyusui (MartinezBrockman et al., 2018). Menurut Vincent (2015) pelatihan dan dukungan menyusui dapat 
meningkatkan efikasi diri dengan cara mempengaruhi perilaku (Bandura \& Adams, 1977) melalui observasi perilaku orang lain (Bandura, 1977) sehingga berdampak positif pada proses menyusui. Oleh sebab itu, pemberian dukungan menyusui dari pasangan, nenek, dan teman sebaya menyediakan pengalaman dan perilaku yang diharapkan dapat meningkatkan hasil menyusui yang lebih baik.

Pengalaman tentang ibu yang kontak dengan pendukung sebaya dijelaskan dari studi kualitatif Niela-Vilen et al. (2015) yang merekomendasikan dukungan tambahan dari pendukung sebaya berbasis internet untuk berbagi pengalaman menyusui diantara ibu dan pendukung sebaya. Temuan tersebut konsisten dengan studi kualitatif terdahulu yang dilakukan oleh Rossman et al. (2011). Rossman et al. mengungkapkan ketekunan ibu dalam melakukan kontak dengan konselor sebaya dapat menambah informasi, menerima bantuan praktik, dan dukungan menyusui serta memerah ASI untuk mempertahankan produksi ASI. Selain itu, berbagi pengalaman diantara ibu dan konselor sebaya membuat ibu merasa mendapat dukungan, sehingga dapat membatu ibu bertahan menyusui.

\section{Variasi Intervensi Dukungan Menyusui untuk Mempromosikan Pemberian ASI bagi Neonatus}

Intervensi dukungan menyusui dari keluarga dan teman sebaya telah diuji oleh para peneliti. Pemilihan pendukung menyusui perlu memperhatikan karakteristik individu yang memberi dukungan menyusuin. Adapun kriteria nenek yang akan menjadi pendukung sebaya adalah nenek tinggal bersama atau tinggal dekat dengan ibu menyusui, berpengalaman merawat bayi, dan berusia diantara 35-60 tahun (Bootsri \& Taneepanichskul, 2017). Sementara itu kriteria pendukung sebaya adalah wanita yang memiliki pengalaman menyusui serupa dengan target yang akan didukung (Niela-Vilen et al., 2016) dan berpengalaman menyusui lebih dari 4 minggu (Meglio et al., 2010).

Peneliti ada yang tidak memberikan pendidikan khusus bagi pendukung ibu menyusui (Niela-Vilen et al., 2016), namun sebagian besar peneliti memberikan sesi pelatihan atau pendidikan tentang menyusui kepada pendukung menyusui. Materi pendidikan tentang menyusui dapat diberikan dalam 6 jam (2 hari) (Bootsri \& Taneepanichskul, 2017), pelatihan 10 sesi 2 jam bagi konselor sebaya (Meglio et al., 2010), dan 6 kali sesi konseling ( da Silva et al., 2016; Oliveira et al., 2014). Pelatihan atau pendidikan tersebut diberikan secara terpisah atau bersamaan dengan ibu menyusui, diberikan pada persiapan awal atau bersamaan dengan sesi konseling dengan ibu, dan diberikan selama di rumah sakit hingga di rumah.

Media edukasi yang digunakan dapat berupa flipchart, booklet, video dan web yang berisi informasi tentang menyusui. Selain memberikan informasi yang tepat, penggunaan metode yang sesuai dengan kebutuhan ibu menyusui menjadi bagian penting untuk diperhatikan oleh tenaga kesehatan agar intervensi efektif. Materi pendidikan dan diskusi meliputi manfaat menyusui, fungsi payudara, produksi ASI, perlekatan dan memposisian bayi, memerah ASI, penyimpanan ASI, memberi bayi minum ASI, mengatasi masalah menyusui, dan peran nenek dalam memberikan dukungan menyusui bagi ibu (Bootsri \& Taneepanichskul, 2017; da Silva et al., 2016; Oliveira et al., 2014). Peneliti lain juga menambahkan mengenai faktor-faktor yang mempengaruhi produksi ASI, bahaya penggunaan botol susu, dan isyarat bayi (da Silva et al., 2016; Oliveira et al., 2014). Nenek diberikan pengetahuan dan praktik menyusui di bangsal persalinan (Bootsri \& Taneepanichskul, 2017). Selanjutnya, sesi konseling yang dilakukan di rumah lebih fokus pada kendala dan masalah yang dihadapi ibu dalam menyusui, manajemen pemberian makanan bayi dan mengulang informasi yang telah diberikan di bangsal untuk penguatan (da Silva et al., 2016; Oliveira et al., 2014). Martinez-Brockman et al. (2018) menggunakan metode yang lebih mudah dalam membagi informasi melalui pemanfaatan teknologi untuk mengirimkan pesan yang berisi informasi tentang manfaat menyusui bagi ibu dan manfaat ASI bagi bayi, memberi contoh yang tepat cara mempromosikan ASI, menjelaskan cara mengetahui kecukupan asupan ASI bagi bayi, merekonstruksi kepercayaan yang salah tentang mitos menyusui, dan memperkukuh peran konselor sebaya (Martinez-Brockman et al., 2018). 
Ragam bentuk dukungan menyusui dibuat oleh peneliti mancanegara. Terjadi pergeseran bentuk intervensi tunggal menjadi multipel intervensi. Di tahun 2010 hingga 2016 bentuk intervensi masih cenderung pada pemberian dukungan tunggal seperti pemanfaatan teknologi komunikasi berupa telepon dari pendukung sebaya (Meglio et al., 2010) atau dukungan sebaya berbasis media sosial (Niela-Vilen et al., 2016), sesi konseling bersama ibu dan pendukung menyusui (nenek) (da Silva et al., 2016; Oliveira et al., 2014). Beberapa peneliti telah menunjukkan hasil keefektifan intervensi pemberian dukungan menyusui, meskipun diantara penelitian tersebut masih terdapat bukti yang belum menunjukkan dampak positif intervensi. Oleh sebab itu, pengembangan multipel intervensi dilakukan meliputi dukungan menyusui co-parenting multifaset bagi ibu primipara multikultural (Abbass-Dick et al., 2015), Experiential Learning with Empowerment Strategies and Social Support (ELESSS) (Bootsri \& Taneepanichskul, 2017), dan kombinasi intervensi Lactation Advice Through Texting Can Help (LATCH) dengan program standar WIC-BFPC (Women, Infants, and Children-Breastfeeding Peer Concelors) (Martinez-Brockman et al., 2018).

Di Indonesia, intervensi untuk mempromosikan ASI sebaiknya memperhatikan aspek kultural yang dapat menjadi hambatan dalam pemberian ASI. Para peneliti di Indonesia menemukan bahwa hambatan dalam meningkatkan pemberian ASI di rumah sakit adalah keterbatasan akses ibu menyusui dengan tenaga kesehatan, menyusui non-ekslusif dianggap sebagai hal yang normal, kepercayaan bahwa susu formula lebih baik untuk bayi (Flaherman et al., 2018), pemahaman yang salah mengenai kolostrum, dan penempatan neonatus terpisah dari ibu agar ibu dapat beristirahat paska operasi (Titaley, Loh, Prasetyo, Ariawan, \& Shankar, 2014). Berdasarkan beberapa temuan tersebut, maka pendidikan kesehatan yang memadai terkait menyusui harus terus-menerus dilakukan agar ibu mendapat informasi yang benar dan dapat memperbaiki persepsi ibu dan keluarga.

Berbagai intervensi untuk mempromosikan ASI di Indonesia telah dilakukan diantaranya intervensi kelas ibu berupa pemberian informasi tentang kehamilan dan perawatan neonatus (Nasir, Amran, \& Nakamura, 2017). Selanjutnya intervensi dukungan menyusui oleh teman sebaya dan tenaga professional secara online (Dewanti, Februhartanty, \& Roshita, 2019). Sementara itu, di tatanan pelayanan kesehatan primer, pembentukan Asosiasi Ibu Menyusui Indonesia (AIMI) dapat menguatkan dukungan menyusui dari keluarga (terutama suami) dan teman sebaya (Handajani, Pamungkasari, \& Budihastuti, 2018). Ragam intervensi tersebut memberikan dampak positif bagi ibu menyusui.

Pendekatan multi-sektoral dapat digunakan sebagai strategi yang komprehensif untuk mempromosikan ASI di Indonesia (Titaley et al., 2014) maupun di mancanega. Gencarnya promosi susu formula di Indonesia, kurangnya kerjasama orang tua, dan kurang optimalnya implementasi kebijakan di rumah sakit terkait ASI membuat target pencapaian ASI eksklusif di Indonesia terkendala. Menurut Tahir dan Al-Sadat (2013) metode tunggal dukungan menyusui tidak efektif untuk jangka panjang, sehingga penelitian lebih lanjut perlu dilakukan terhadap pemodelan intervensi yang dapat mempromosikan pemberian ASI bagi neonatus dan memenuhi kebutuhan berbeda selama masa ibu menyusui.

\section{SIMPULAN}

Dukungan menyusui dari pasangan, nenek, dan teman sebaya efektif meningkatkan hasil menyusui bagi ibu postpartum di rumah sakit, sehingga direkomendasikan sebagai intervensi untuk meningkatkan prevalensi pemberian ASI. Metode intervensi multipel lebih efektif dibandingkan intervensi dukungan tunggal. Perawat hendaknya mengkombinasi potensi dukungan dari keluarga dan teman sebaya dengan berbagai metode untuk mencapai hasil yang lebih baik dalam mempertahankan menyusui. Kajian ini belum mencakup hasil menyusui yang berdampak pada bayi. Demikian juga penggunaan media sosial sebagai media komunikasi dalam memberikan dukungan menyusui belum menunjukkan bukti yang kuat dari efek positif suatu intervensi. Oleh sebab itu, membutuhkan penelitian lebih lanjut untuk mengonfirmasi pengaruh intervensi berbasis media sosial dan pengaruh dukungan menyusui terhadap bayi terutama bayi yang lahir dari ibu yang berisiko tinggi tidak melanjutkan pemberian ASI. 


\section{DAFTAR PUSTAKA}

Abbass-Dick, J., Stern, S. B., Nelson, L. E., Watson, W., \& Dennis, C.-L. (2015). Coparenting breastfeeding support and exclusive breastfeeding: A randomized controlled trial. Pediatrics, 135(1), 102-110. https://doi.org/10. 1542/peds.2014-1416.

Al Juaid, D. A. M., Binns, C. W., \& Giglia, R. C. (2014). Breastfeeding in Saudi Arabia: A review. International Breastfeeding Journal, 9(1), 1-9. https://doi.org/10.1186/1746-43589-1.

Bootsri, W., \& Taneepanichskul, S. (2017). Effectiveness of experiential learning with empowerment strategies and social support from grandmothers on breastfeeding among Thai adolescent mothers. International Breastfeeding Journal, 12(37), 1-9. https:// doi.org/10.1186/s13006-017-0128-7.

Choiriyah, M., Hapsari, E. D., \& Lismidiati, W. (2015). Tradisi dan lingkungan sosial memengaruhi dukungan menyusui pada bayi berat badan lahir rendah di kota Malang. Kesmas: Jurnal Kesehatan Masyarakat Nasional, 10(1), 37-43. https://doi.org/ 10.21109/kesmas.v10i1.816.

Cleminson, J., Oddie, S., Renfrew, M. J., \& McGuire, W. (2014). Being baby friendly: Evidence-based breastfeeding support. Archives of Disease in Childhood: Fetal and Neonatal Edition, 100(2), F1-F6. https:// doi.org/10.1136/archdischild-2013-304873.

da Silva, C. F., Nunes, L. M., Schwartz, R., \& Giugliani, E. R. J. (2016). Effect of a probreastfeeding intervention on the maintenance of breastfeeding for 2 years or more: Randomized clinical trial with adolescent mothers and grandmothers. BMC Pregnancy and Childbirth, 16(97), 1-6. https://doi.org/ 10.1186/s12884-016-0878-z.

Dewanti, L. P., Februhartanty, J., \& Roshita, A. (2019). Online mother support group: The new way of peer support for improving breastfeeding performance. Journal of Health Education, 4(1), 22-28. https://doi.org/ 10.1080/10556699.1994.10603001.

Flaherman, V. J., Chan, S., Desai, R., Agung, F. H., Hartati, H., \& Yelda, F. (2018). Barriers to exclusive breast-feeding in Indonesian hospitals: A qualitative study of early infant feeding practices. Public Health Nutrition, 21(14), 1-9. https://doi.org/10.1017/ S1368980018001453.
Handajani, D. O., Pamungkasari, E. P., \& Budihastuti, U. R. (2018). Effectiveness of health promotion by Indonesian Breastfeeding Association in increasing exclusive breastfeeding coverage in Surabaya City, East Java. Journal of Health Promotion and Behavior, 3(1), 1-15. https://doi.org/ 10.26911/thejhpb.2018.03.01.01.

Horbar, J. D., Ehrenkranz, R. A., Badger, G. J., Edwards, E. M., Morrow, K. A., Soll, R. F., ... Bellù, R. (2015). Weight growth velocity and postnatal growth failure in infants 501 to 1500 Grams: 2000-2013. American Academy of Pediatrics, 136(1), 84-92. https://doi.org/ 10.1542/peds.2015-0129.

Ikonen, R., Paavilainen, E., \& Kaunonen, M. (2015). Preterm infants "mothers" experiences with milk expression and breastfeeding: An integrative review. Advances in Neonatal Care, 15(6), 394-406. https://doi.org/10. 1097/ANC.0000000000000232.

Kositamongkol, S., Nanthakomon, T., \& Nukaw, S. (2019). A quality improvement project to improve human milk feeding rate in hospitalized neonates. Journal of Pediatric and Neonatal Individualized Medicine, 8(1), 3-7. https://doi.org/10.7363/080111.

Lawn, J.E., Blencowe, H., Oza, S., You, D., Lee, A.C., Waisman, P., ... Cousens, S.N. (2014). Every newborn: Progress, priorities, and potential beyond survival. The Lancet, 384(9938), 189-205.

Luong, K. C., Nguyen, T. L., Thi, D. H. H., Carrara, H. P. O., \& Bergman, N. J. (2016). Newly born low birthweight infants stabilise better in skin-to-skin contact than when separated from their mothers: A randomised controlled trial. Acta Paediatrica, International Journal of Paediatrics, 105(4), 381-390. https://doi.org/10.1111/apa.13164.

Martinez-Brockman, J. L., Harari, N., SeguraPérez, S., Goeschel, L., Bozzi, V., \& PérezEscamilla, R. (2018). Impact of the Lactation Advice Through Texting Can Help (LATCH) Trial on Time to First Contact and Exclusive Breastfeeding among WIC Participants. Journal of Nutrition Education and Behavior. https://doi.org/10.1016/j.jneb.2017.09.001.

Meglio, G. Di, McDermott, M. P., \& Klein, J. D. (2010). A randomized controlled trial of telephone peer support's influence on breastfeeding duration in adolescent mothers. Breastfeeding Medicine, 5(1), 41-47. https://doi.org/10.1089/bfm.2009.0016. 
Nasir, N. M., Amran, Y., \& Nakamura, Y. (2017). Changing knowledge and practices of mothers on newborn care through mother class: An intervention study in Indonesia. Journal of Tropical Pediatrics, 63(6), 440-446. https://doi.org/10.1093/tropej/fmx010.

Niela-Vilen, H., Axelin, A., Melender, H.-L., \& Salantera, S. (2015). Aiming to be a breastfeeding mother in a neonatal intensive care unit and at home: A thematic analysis of peer-support group discussion in social media. Maternal and Child Nutrition, 11, 712-726. https://doi.org/10.1111/mcn.12108.

Niela-Vilen, H., Axelin, A., Melender, H. L., Loyttyniemi, E., \& Salantera, S. (2016). Breastfeeding preterm infants - a randomized controlled trial of the effectiveness of an Internet-based peer-support group. Journal of Advanced Nursing, 72(10), 2495-2507. https://doi.org/10.1111/jan.12993.

Oliveira, L. D. de, Giugliani, E. R. J., Santo, L. C. do E., \& Nunes, L. M. (2014). Counselling sessions increased duration of exclusive breastfeeding: A randomized clinical trial with adolescent mothers and grandmothers. Nutrition Journal, 13(73), 1-7. https:// doi.org/10.1186/1475-2891-13-73.

Robinson, K. M. (2016). Perinatal nurses: Key to increasing African American breast-feeding rates. Journal of Perinatal and Neonatal Nursing, 30(1), 3-5. https://doi.org/10.1097/ JPN.0000000000000147.

Rossman, B., Engstrom, J. L., Meier, P. P., Vonderheid, S. C., Norr, K. F., \& Hill, P. D. (2011). "They've Walked in My Shoes": Mothers of very low birth weight infants and their experiences with breastfeeding peer counselors in the neonatal intensive care unit. Journal of Human Lactation, 27(1), 14-24. https://doi.org/10.1177/0890334410390046.

Tahir, N. M., \& Al-Sadat, N. (2013). Does telephone lactation counselling improve breastfeeding practices?: A randomised controlled trial. International Journal of Nursing Studies, 50(1), 16-25. https://doi.org/ 10.1016/j.ijnurstu.2012. 09.006.
Thakur, S. K., Roy, S. K., Paul, K., Khanam, M., Khatun, W., \& Sarker, D. (2012). Effect of nutrition education on exclusive breastfeeding for nutritional outcome of low birth weight babies. European Journal of Clinical Nutrition, 66(3), 376-381. https://doi.org/ 10.1038/ejcn. 2011.182.

Titaley, C. R., Loh, P. C., Prasetyo, S., Ariawan, I., \& Shankar, A. H. (2014). Socio-economic factors and use of maternal health services are associated with delayed initiation and nonexclusive breastfeeding in Indonesia: Secondary analysis of Indonesia Demographic and Health Surveys 2002/2003 and 2007. Asia Pacific Journal of Clinical Nutrition, 23(1), 91-104. https://doi.org/ 10.6133/apjen.2014.23.1.18.

Tufanaru C, Munn Z, Aromataris E, Campbell J, \& Hopp L. (2017). Chapter 3: Systematic reviews of effectiveness. In: Aromataris, E., \& Munn Z. (Editors). Joanna Briggs Institute Reviewer's Manual. The Joanna Briggs Institute. Retrieved from https:// reviewersmanual.joannabriggs.org/.

Vincent, A. (2015). The effect of breastfeeding selfefficacy on breastfeeding initiation, exclusivity, and duration. Walden University.

WHO. (2014). Global nutritional targets 2025: Low birth weight policy brief. Retrieved from https://www.who.int/nutrition/publications/gl obaltargets2025_policybrief_lbw/en/.

WHO. (2012). Born too soon: the global action report on preterm birth. WHO: Geneva.

WHO. (2018). Implementation guidance: Protecting, promoting and supporting breastfeeding in facilities providing maternity and newborn services - The revised Baby Friendly Hospital Initiative. Switzerland: World Health Organization (WHO) \& United Nations Children's Fund (UNICEF). https://doi.org/10.5005/jp/books/11873_19.

Widiastuti, S., Rustina, Y., \& Agustini, N. (2019). Hubungan dukungan sosial dengan motivasi ibu dalam memberikan ASI pada bayi berat lahir rendah (BBLR). Journal Educational of Nursing, 2(2), 46-49. 